\title{
Aquaculture's struggle for space: the need for coastal spatial planning and the potential benefits of Allocated Zones for Aquaculture (AZAs) to avoid conflict and promote sustainability
}

\author{
P. Sanchez-Jerez ${ }^{1, *}$, I. Karakassis ${ }^{2}$, F. Massa ${ }^{3}$, D. Fezzardi ${ }^{3}$, J. Aguilar-Manjarrez ${ }^{4}$, \\ D. Soto ${ }^{4}$, R. Chapela ${ }^{5}$, P. Avila ${ }^{6}$, J. C. Macias $^{7}$, P. Tomassetti ${ }^{8}$, G. Marino ${ }^{8}$, J. A. Borg ${ }^{9}$, \\ V. Franičević ${ }^{10}$, G. Yucel-Gier ${ }^{11}$, I. A. Fleming ${ }^{12}$, X. Biao ${ }^{13}$, H. Nhhala ${ }^{14}$, H. Hamza ${ }^{15}$, \\ A. Forcada ${ }^{1}$, T. Dempster ${ }^{16}$
}

\footnotetext{
${ }^{1}$ Department of Marine Science and Applied Biology, University of Alicante, PO Box 99, 03080 Alicante, Spain

${ }^{2}$ Institute of Marine Biology of Crete, PO Box 2214, 71003 Heraklion, Greece

${ }^{3}$ General Fisheries Commission for the Mediterranean, Food and Agriculture Organisation of the United Nations,
} Via Vittoria Colonna 1, 00193 Rome, Italy

${ }^{4}$ Fisheries and Aquaculture Department, Food and Agriculture Organization of the United Nations, Viale delle Terme di Caracalla, 00153 Rome, Italy

${ }^{5}$ CETMAR, C/ Eduardo Cabello s/n, 36208 Bouzas-Vigo Spain

${ }^{6}$ Junta de Andalucía, Agencia de Gestión Agraria y Pesquera de Andalucía, C/ Severo Ochoa 38, Parque Tecnológico de Andalucía, 29590 Campanillas, Málaga, Spain

${ }^{7}$ Aquaculture Consultant, C/ Crucero $2{ }^{\mathrm{a}} \mathrm{F}$ n1, Sanlúcar de Barrameda, 11540 Cadiz, Spain

${ }^{8}$ Institute for Environmental Protection and Research (ISPRA), Via Vitaliano Brancati 48, 00144 Rome, Italy

${ }^{9}$ Department of Biology, Faculty of Science, University of Malta, 20810 Msida, Malta

${ }^{10}$ Ministry of Agriculture, Department of Fisheries, I. Mažurani a 30, 23000 Zadar, Croatia

${ }^{11}$ Institute of Marine Sciences and Technology, Dokuz Eylül University, 35340 Izmir, Turkey

${ }^{12}$ Department of Ocean Science, Memorial University of Newfoundland, St. John's, NL A1C 5S7, Canada

${ }^{13}$ School of Geography Sciences, Nanjing Normal University, 1 Wenyuan Road, Nanjing 210023, PR China

${ }^{14}$ Centre Aquacole Institut National de Recherche Halieutique, BP n³1, M'diq, Morocco

\footnotetext{
${ }^{15}$ Direction Générale des Pêches et de l'Aquaculture Ministère de l'Agriculture, 30 Rue Alain Savary, 1002 Tunis, Tunisia

${ }^{16}$ Sustainable Aquaculture Laboratory - Temperate and Tropical (SALTT), Department of Zoology, University of Melbourne, Victoria 3010, Australia
}

ABSTRACT: Aquaculture is an increasingly important food-producing sector, providing protein for human consumption. However, marine aquaculture often struggles for space due to the crowded nature of human activities in many marine coastal areas, and because of limited attention from spatial planning managers. Here, we assess the need for coastal spatial planning, emphasising the establishment of suitable areas for the development of marine aquaculture, termed Allocated Zones for Aquaculture (AZAs), in which aquaculture has secured use and priority over other activities, and where potential adverse environmental impacts and negative interactions with other users are minimised or avoided. We review existing examples of marine aquaculture spatial development worldwide and discuss the proper use of site selection in relation to different legal and regulatory requirements. National or regional authorities in charge of coastal zone management should carry out spatial planning defining optimal sites for aquaculture to promote development of sustainable marine aquaculture and avoid conflict with other users, following a participatory approach and adhering to the principles of ecosystem-based management.

KEY WORDS: Site selection $\cdot$ Spatial planning $\cdot$ Aquaculture 


\section{INTRODUCTION}

Aquaculture, including marine aquaculture (mariculture), plays a major role in meeting the rising demand for fish products and supplying healthy and nutritious protein to a growing global population (Larsen \& Roney 2013). Proponents of aquaculture have called for increased fish production from mariculture to increase fish delivery for human consumption, to reduce the use of scarce natural resources such as freshwater (Duarte et al. 2009) and wild fish (FAO 2012a), and because of the economic benefits. If mariculture is to expand, access to adequate areas for production will be a key determinant of future production levels because, despite calls to 'conquer the ocean' with offshore mariculture (Marra 2005), for the moment coastal waters remain the most desirable location for marine aquaculture.

However, available space for new mariculture development in coastal zones is now becoming increasingly limited. This trend can be expected to continue because, along with aquaculture, other human activities in coastal and oceanic waters will increase significantly over the next $20 \mathrm{yr}$, including tourism (Hall 2001) and offshore renewable energy generation (Douvere \& Ehler 2009). Traditional activities, such as capture fisheries, are deeply embedded in many coastal communities and they will continue to play an important role in the use of nearshore coastal seascapes. This competition for space has resulted in negative interactions with traditional and new coastal users (Dempster \& Sanchez-Jerez 2008), and negative effects of other activities on aquaculture (e.g. agriculture and sewage discharges; Díaz et al. 2012). The complex interactions among users of coastal areas often leave little space for aquaculture, particularly since marine aquaculture requires coastal waters with specific environmental and water quality characteristics. The result is that suitable coastal areas for aquaculture are severely limited in many areas and this has become a major barrier to expansion.

The seventh session of the Sub-Committee on Aquaculture (SCA) of the FAO Committee on Fisheries expressed a strong interest in spatial planning to ensure the allocation of space for aquaculture growth. The SCA acknowledged that spatial planning needs to follow an ecosystem approach and to define socioeconomic, environmental and governance objectives that result in the integrated management of land, water and living resources for the development and expansion of the sector in a sustainable and equitable way (FAO 2013a). Therefore, to ensure a balance between conserving ecosystem services and other legit- imate uses of marine resources, spatial planning of aquaculture activities through optimal site selection is necessary.

The purpose of this paper is to review some examples of spatial planning in marine waters across the world to assist aquaculture development. We discuss the potential benefits of establishing suitable areas for the development of marine aquaculture, Allocated Zones for Aquaculture (AZAs), in which aquaculture has priority over other activities, and where adverse environmental and social impacts, as well as negative interactions with other users, are minimised or avoided, and propose key considerations for the successful implementation and management of AZAs.

\section{SPATIAL PLANNING OF MARINE AQUACULTURE}

\section{Identifying optimal sites}

The success of an aquaculture project depends to a large extent on the selection of an appropriate site to establish the farm; this entails an intricate multicriteria decision-making process. For site selection, in addition to consideration of physical and environmental factors, other crucial aspects concerning the efficiency and economy of the aquaculture operations are central (see Ross et al. 2013 for an extensive description of the area and site selection process). The producer must identify the marketability of the product, after making a proper evaluation of existing demand and its stability, and of potential future markets (Knapp 2008). Once a market has been identified, a suitable site for production must be found which is in accordance with the biology of the cultivated organism and the projected volume of production. Haphazard development of aquaculture without adequate planning and regulation can lead to adverse environmental impacts, lack of economic feasibility, and/or social conflicts. Negative environmental and social conflicts have emerged at broad scales previously where planning has been inadequate, such as seen in the early development of prawn farming in tropical regions (Primavera 1997, Pattanaik \& Prasad 2011).

Spatial planning of aquaculture activities should be a public process aimed at achieving ecological, economic, and social objectives that usually have been specified through a governance process, with a broad participatory approach (IUCN 2009, FAO 2013b, Ross et al. 2013, Hishamunda et al. 2014). Essentially, spatial planning contributes to the process of selecting suitable areas and sites for aquacul- 
ture when it is integrated and forward-looking with respect to regulation, management and protection of the marine environment; the allocation of space should address the multiple, cumulative, and potentially conflicting uses of the sea (FAO 2013b). The shared use of public domain areas and the conservation policies adopted for coastal areas reduce the availability of sites. At the same time, however, the demand for aquaculture products is increasing, especially because this activity can supply a constant stream of quality products at stable prices (FAO 2010a).

Preliminary site selection processes should define the geographical location and extent of aquaculture in a determined region (Ross et al. 2013). As part of this process, physical, ecological and socio-economic criteria should be taken into account. Next, a location that minimises conflict with the other users of coastal waters, such as shipping, fishing, recreational activities and the energy industry (Dempster \& SanchezJerez 2008), should be identified to site the farm. As aquaculture is often the 'new kid on the block' in terms of its use of space, in many coastal areas it will be difficult to find suitable sites which do not conflict with pre-existing uses that may well be considered more important socio-economically for the region (Toledo-Guedes et al. 2014). As this scenario of multiple pre-existing uses of coastal spatial resources is widespread, we suggest that the AZA concept should be considered to provide space for marine aquaculture, and avoid environmental degradation and negative interaction with other traditional users. Here, we define an AZA as: 'a marine area where the development of aquaculture has priority over other uses, and therefore will be primarily dedicated to aquaculture. Identification of an AZA will result from zoning processes through participatory spatial planning, whereby administrative bodies legally establish that specific spatial areas within a region have priority for aquaculture development'.

FAO (2010b) defines an Ecosystem Approach to Aquaculture (EAA) as a strategy for the integration of the activity within the wider ecosystem context that promotes sustainable development, equity and resilience of interlinked socio-ecological systems. A key principle of this approach is that aquaculture development and management should take account of the full range of ecosystem functions and services, and should not threaten the sustained delivery of these to society. Aquaculture should be developed in the context of ecosystem functions, which entails estimating assimilative and production carrying capacities, and adapting farming practices considering both ecological and social components. The EAA provides the strategy including steps, process and tools to facilitate the definition of AZAs. This was recently proposed by Ross et al. (2013).

Another consideration is that aquaculture should help improve human well-being and equity for local communities. Following the IUCN (2009) and FAO recommendations (Ross et al. 2013), selection of AZAs should be based on a participatory approach. It should promote social acceptability by applying the precautionary principle, and consider the potential of adaptive management. Based on these principles, political decisions on the use of coastal space, following spatial planning, should favour aquaculture in coastal regions with reduced social confrontation. Therefore, AZAs should be identified in all coastal areas where a potential space for aquaculture exists, and be included in national and regional administrative structures alongside other sectors, serving as a tool for the integration of aquaculture into coastal zone management (Chapela Pérez 2009). It is clear, however, that the designation of an AZA is not enough to guarantee sustainable aquaculture. Within an AZA, the specific site selection and the production per site must match ecosystem carrying capacities and a permanent monitoring programme within the relevant water body (which could be an AZA) is needed to assess the impacts of each farm. Other potential issues, such as diseases, can be spread in AZAs and therefore biosecurity aspects must also be considered (Ross et al. 2013).

\section{Allocation of mariculture in different regions}

Spatial planning for selection of AZAs is already widespread globally, although they exist under very diverse legislative and administrative arrangements and are referred to by an array of names. Here, we provide key examples from each global region to demonstrate how spatial planning is implemented and how the concept of AZA has been flexibly implemented in regions with different legal and regulatory frameworks.

\section{Europe}

In the Mediterranean region, the development of European seabass Dicentrarchus labrax and gilthead seabream Sparus aurata culture is of high economic importance, but this been hindered by existing heavy use of the coastal zone and competition with many other users. Consequently, spatial planners have 
established AZAs across the region. Chapela \& Ballesteros (2011) review the procedures for site selection, regulatory schemes and environmental impact assessment (EIA) processes undertaken by different Mediterranean countries.

In Italy, the legislative framework for marine aquaculture is heterogeneous across regions. This is because of the transfer of most administrative, regulative and control functions related to agriculture, fisheries and aquaculture from the Italian Ministry of Agricultural, Food and Forestry Policies and the Italian Ministry for Environment and Territory and Sea (MATTM) to the Regional Authorities (Decree 143, 4 Jun 2007). Only a few Italian regions have developed rules and guidelines for aquaculture development and monitoring. In 2008, the Sicilian region issued 'Guidelines for the setting-up of marine fish farms' (ARPA Sicilia 2008), which includes site selection criteria and a monitoring programme based on the relationship between the hydrodynamic regime and other environmental conditions, and the farmed fish biomass. The Liguria region issued 'Criteria and directives for marine aquaculture' (Committee Decree 1415, 30 Nov 2007), while the Toscana region provided guidelines and provisions for the application of EIA to fish farms (Regional Law 68, 18 Apr 1995). All these new regional regulations adopt an AZA approach and include guidelines for an environmental monitoring programme. The Emilia Romagna region set up the Information System for the Sea and the Coasts (SIC) as a decision-making tool to support integrated coastal zone management (ICZM) activities. In this framework, SICs support multiple uses of coastal areas (e.g. fisheries, mussel culture, oil platforms), with an interactive cartography based on geographic information system (GIS) tools. The Marches Regional Council issued a decision (18 Oct $2005)$ to identify public areas for aquaculture mainly based on socio-economic and environmental aspects. The Puglia Regional Council approved a specific law (no. 17, 23 Jun 2006) for the 'Plan of Regional Coasts', where, for further development of aquaculture activities, fish farms need to be certified by the European Eco-Management and Audit Scheme or as organic farms.

At the national level, the Protocol on Mediterranean ICZM (EU Official Journal L34/19, 4 Feb 2009) has been implemented by MATTM, through the institutional cooperation between the ministry and local public authorities. The protocol includes some recommendations on aquaculture, related to identifying allocated areas for aquaculture where these activities are under development, and the management of aquaculture wastes and the production process. The national Legislative Decree 152/2006 on the Protection of Waters against Pollution includes Article 111, which is specifically related to aquaculture. Pursuant to this article, a specific set of rules will be issued, that include the application of AZA principles. In June 2012 a new Legislative Decree (83/2012) transferred responsibility for issuing fish farm licenses to the Ministry of Agricultural, Food and Forestry Policies. It is expected that future integration of these 2 new pieces of legislation will provide a clearer legislative framework for aquaculture development in coastal areas and for implementation of AZAs.

In Spain, as in Italy, regional communities are responsible for coastal spatial planning. Thus, aquaculture site selection programmes are at various stages of development depending on region. As an example, in the region of Andalucía, planning and management of aquaculture activities fall under the responsibility of the Regional Ministry of Agriculture and Fisheries. In this region, studies for site selection since 2001 have been based on data collection and analysis using GIS for aquaculture planning and development. The first step in the process is to identify all users of the coastal zone and the roles of the different administrative bodies that have jurisdiction over the activities within the zone (Macías et al. 2006). This is followed by an environmental assessment of the identified areas (Macías et al. 2006). Studies undertaken in the final stages of the process address socio-economic aspects and consider the need for specific regulations for given species (Order 2006-BOJA/76, 10 Apr 2006). These studies and regulations are then applied to identify areas suitable for aquaculture within the whole Maritime Public Domain in the Region.

In Malta, the concept of 'Offshore Aquaculture Zones' (a synonym of AZA) originated in the mid2000s from the need to translocate existing tuna farms offshore and to provide additional sites for new tuna ranches and other fish farms. The first such site, located $6 \mathrm{~km}$ off the southeastern coast of Malta, was established in 2006, and is managed by the Fisheries and Aquaculture Department of the Ministry for Sustainable Development, the Environment and Climate Change. Establishment of the Maltese AZA required an environmental impact statement (EIS) as per the requirements of the Malta Environment and Planning Authority (MEPA). The EIS included studies on aspects of feasibility and socio-economics, and of the marine environment, notably the benthic habitats present in the area. The Maltese AZA currently has 2 tuna farms operating within it, but the site has been designated to support a maximum of 6 farms. Alloca- 
tions are on a lease basis and the fish farms operating within the site are required to undertake regular environmental monitoring as per the MEPA's guidelines.

Although Croatia has optimal natural conditions and a long tradition in aquaculture, the development of aquaculture has not proceeded as rapidly as in neighbouring Mediterranean countries. One of the main obstacles for its development has been delays in the selection of locations for aquaculture activities. Over the past decade, Croatia has developed a legal framework in order to define basic spatial requirements for different aquaculture activities, as well as requirements for EIA procedures. These measures have resulted in significant development of the sector. There are 7 administrative regions on Croatia's coastline. In these regions, AZAs are identified within physical plans. Basic biophysical criteria for AZAs are defined by specific national legislation. In addition to biophysical criteria, this legislation prescribes criteria regarding the availability of the necessary infrastructure. Based on the analysis of natural conditions and anthropogenic activities, areas that are excluded for aquaculture are defined (e.g. urban centres, military zones and areas of intensive maritime traffic). Aquaculture in protected areas, including NATURA 2000 sites (European Commission 2014), requires special authorisation. The permits for locations of aquaculture farms within an AZA must align with the physical plan. A permit is issued following an EIA that takes account of the species, production technique and production quantities. The EIA also defines future monitoring procedures. Based on the location permits, regional administrations then allocate concessions for aquaculture production for a maximum period of $20 \mathrm{yr}$. Final aquaculture licenses are issued by the Ministry of Agriculture based on the concession agreement and results of the EIA.

In Greece, the long size of the coastline, low level of development and lack of adequate funding and human resources resulted in a rather inadequate national plan for the development of the coastal zone. Since the beginning of the 1980s, fish farming has grown rapidly in sheltered, shallow coastal sites. Since the vast majority of fish farmers have applied for sites in remote, undeveloped areas, most licenses awarded before the 2000s were assigned without broader examination of the suitability of the area or assessment of the cumulative effects of multiple farms. After the Council of State cancelled all the acts of the administration regarding new licenses, a new planning system for fish farming was implemented. This includes 3 types of planning schemes for designated Areas for Development of Aquaculture: (1) the
POAY (acronym of the respective Greek terminology: areas of organised development of aquaculture) which follows the typical AZA concept, with a leased area of at least 10 ha and with coordinated management and monitoring of the farms; (2) the PASMI (acronym of the respective Greek terminology: areas of scattered concentrations of fish farming) with less than 5 farms, a farmed area less than 10 ha and a distance between farms of between 500 and $2000 \mathrm{~m}$; and (3) individual farms mainly in remote areas which have specific limits placed on area and maximum production. The new regulation in Greece requires that farms in AZAs should be located at least $1000 \mathrm{~m}$ away from urban sites, tourist facilities, harbours, industrial areas, mining and other incompatible activities, and at least $500 \mathrm{~m}$ from diving centres and major swimming beaches. Establishment of a POAY requires extensive comprehensive EIA, including measurement of sea currents, mapping of habitats and sampling of biological and physico-chemical variables. POAYs are established by a Presidential Decree and require a management operator and a plan for the management, monitoring and restoration of the area.

Cage fish farming of European seabass and gilthead seabream began in the Turkish Aegean in 1986. Initially, farming took place in sheltered, shallow coastal areas between Izmir and Mugla along the Aegean coastline. In parallel with an increase in aquaculture production, there was a marked development of urbanisation and tourism. This generated conflicts among different uses of the area. New legislation was developed which led to relocation of fish farming offshore. This new legislation prohibited the siting of farms in locations shallower than $30 \mathrm{~m}$ depth and closer than 0.6 nautical miles from the shore. Furthermore, it considered eutrophication values using TRIX Index as a guideline for selection of AZAs (MEF 2007). According to the legal framework, 2 large AZAs at Milas and Bodrum were defined by the InterMinisterial consortium in 2007. Before the establishment of the 2 AZAs, an EIA was undertaken. Annually, each farm must be reassessed by the Ministry of Environment and Forestry for water column and sediment attributes within the Environmental Monitoring Programme (MEF 2009).

\section{Oceania and Asia}

A similar approach to spatial management to that of AZA is exemplified by the adoption of Aquaculture Management Areas (AMA) in New Zealand. 
The aquaculture industry has experienced rapid recent growth, with more than 500 greenshell mussel Perna canaliculus farms in operation that cover a combined total area of $30 \mathrm{~km}^{2}$. Rapid industry growth, coupled with the near saturation of traditional sites and advances in culture technologies, have led the industry offshore. The industry's desire to explore offshore areas, together with recent central government requirements, has created the need for environmental managers to designate zones for aquaculture through the creation of AMAs (Longdill et al. 2008). In November 2010, the Minister of Conservation released a revised New Zealand Coastal Policy Statement, providing stronger direction and recommendations on how coastal environment must be managed in different regions, including requiring the spatial identification of important elements. An example of the application of this policy is the Hauraki Gulf Marine Park Act 2000. This management plan includes integrated management of the gulf, including aquaculture, protection and enhancement of the resources and life-supporting capacity of the gulf's environment (Hauraki Gulf Forum 2011). This example underscores that AMAs go beyond AZAs, since after the zoning there is the development of a management plan for the AMA, and this is followed up by permanent monitoring, periodic evaluation and adaptive management measures. This is in full agreement with the recommended steps for EAA implementation (FAO 2010b).

In Australia, a recent example of AZA implementation can be seen in the development of a regional marine aquaculture management plan for coastal waters of the Sandy Straits region in Queensland (State of Queensland 2011). The Great Sandy Regional Marine Aquaculture Plan established guidelines and identified suitable zones for marine aquaculture development, which lie within a larger area of a marine park, where there was an array of zoned areas with different levels of protection. The AZAs were chosen after a consultation process between industry and government to minimise conflict with other user groups and ensure that social and environmental assets of the marine park were not compromised. Management controls were developed during the process, to reduce the risk of adverse impacts on these assets. These controls provide rules to be applied to aquaculture activities and specify the conditions under which aquaculture farms can operate, including infrastructure and design requirements, environmental requirements, specifications for ongoing environmental monitoring programmes and measures to ensure biosecurity.
In China, with the establishment of a research group by the State Aquaculture Administration in 1978, technological development allowed the intensification of aquaculture and production grew dramatically, from less than 1.3 million $t$ in 1970 to approximately 47.8 million $\mathrm{t}$ in 2010 , by which time it accounted for $61.2 \%$ of the total global aquaculture production by weight, and representing $49.3 \%$ of the total global aquaculture production by value (FAO 2012b). Aquaculture in China is a diverse industry, which includes production of a variety of fish, crustaceans, shellfish and algae. Marine aquaculture covers 2.08 million ha (MABF 2011), it is mostly carried out in shallow seas, mud flats and sheltered bays and also includes land-based installations (Cao et al. 2007). Geographically, China's marine aquaculture activities are divided in 3 sectors: the Bohai Sea and Yellow Sea culture zone, the southeast coastal culture zone and the Yangtze Valley culture zone. In general, 2 main factors affect aquaculture site selection in China: the local functional zoning plan and the Regulation on Water Quality and Effluent from Aquaculture. Thus, the coastal areas must fit the local functional zoning plan, considering that ownership of land and water areas in China is public. For example, the Functional Zoning Scheme of the Coastal Areas of Guangdong region was issued in 1999, which specified division of the coastal area into different 'function zones', including aquaculture. In 2004, the 'Aquaculture Plan for Inland Water Areas and the Coastal Zone of Guangdong' was approved by the provincial government, establishing guidelines for aquaculture development and management by local authorities.

\section{North and South America}

While Canada has a number of policy documents designed to provide a framework for sustainable aquaculture (reviewed in VanderZwaag et al. 2012), it lacks specific federal legislation to address it. Among the various policy documents, the National Aquaculture Strategic Action Plan Initiative 20112015 is the most overarching and is endorsed by federal and regional governments. It is designed to provide a strategic vision for aquaculture development based on environmental protection, social well-being and economic prosperity. Despite such a policy framework, Canada continues to rely on a complex patchwork of more than 70 pieces of federal and regional legislation to regulate the industry. Thus, Canada needs to develop and enact modern inte- 
grated legislation along the lines of a sustainable aquaculture act that specifies requirements and guidance on national objectives and procedures for all aquaculture operations (Hutchings et al. 2012). This is recognised and called for by industry, stakeholders and non-governmental organisations alike (VanderZwaag et al. 2012).

On the Pacific coast, Fisheries and Oceans Canada is in the process of developing Integrated Management of Aquaculture Plans for aquaculture licensing that include spatial planning of aquaculture sites. The region of British Columbia remains involved in assessing land tenure applications for aquaculture facilities during the transition to federal regulation. While more of the regulation of finfish aquaculture falls within the purview of regional governments on Canada's Atlantic coast, the federal government retains the authority to be consulted on and to provide recommendations regarding the issue of leases or extension of those already issued by regions. As a result, the regulatory frameworks have been largely site-specific, developed locally or regionally, and have not been reconciled with each other around the country (DFO 2005). To date, however, integrated management efforts and accomplishments have been limited (Jessen 2011, VanderZwaag et al. 2012). It remains for Canada to develop marine spatial planning with clear geographical priorities, explicit timelines and transparent measures for public reporting (Hutchings et al. 2012).

In United States of America, the 2011 Department of Commerce and National Oceanic and Atmospheric Administration aquaculture policies as well as the National Ocean Policy, provide federal guidance for marine aquaculture activities (NOAA 2011). Projects that are sited in USA waters must meet a suite of federal, state, and local regulations that ensure environmental protection, water quality, food safety, and protection of public health. Currently, the first comprehensive regional approach to authorising aquaculture in federal waters is being developed through a Fishery Management Plan for Regulating Offshore Marine Aquaculture in the Gulf of Mexico (GMFMC \& NOAA 2009). The purpose of this 'Gulf Aquaculture Plan' plan is to maximise benefits to the nation through the development of an environmentally sound and economically sustainable aquaculture industry in federal waters of the Gulf of Mexico. The plan establishes a regional permit process and includes a first approach to marine spatial planning. The plan would allow up to 20 offshore aquaculture operations to be permitted in federal waters of the gulf over a $10 \mathrm{yr}$ period. At a regional scale, there are a few examples of marine spatial planning. In Florida, for example, the process of site selection for farms growing Mercenaria spp. has been described by Arnold et al. (2000).

In Ecuador, which supports an important crustacean culture industry, the national government has adopted a law on fisheries and aquaculture planning called the Management Plan of Fisheries and Aquaculture (Official Register 14, 4 Feb 2003; Arriaga \& Martinez 2003). This management plan enforces the zoning of marine and coastal areas, including the selection of AZAs.

The General Law of Fisheries and Aquaculture of the Chilean Government (Article 67) defines Suitable Areas for Aquaculture (AAA, from the Spanish term 'Areas Aptas para la Acuicultura'). AAAs are areas under public ownership that, following consultation with competent authorities, are entitled to contain aquaculture production (SUBPESCA 2014). The AAAs are selected by regions along the Chilean coast, and their designation should be published in the Official Journal of the Republic of Chile. Other activities can be carried out in these AAAs, and all types of aquaculture can be developed (from shore based to open water). However, the Chilean salmon farming industry was strongly affected by infectious salmon anaemia (ISA) disease, which is spread within aquaculture areas (Niklitschek et al. 2013). This might indicate that the selection of AZAs was not correctly carried out.

\section{Africa}

In Morocco, shellfish culture (the oyster Crassostrea spp.) first started on the Atlantic coast (Lagoon of Oualidia) in the 1950s, while fish culture (gilthead seabream and European seabass) began first on the Mediterranean coast (Lagoon of Nador) in 1986. Aquaculture took place in sheltered sites until the 1990s, after which coastal aquaculture installations began to proliferate. Floating cages were used for fish culture in the Mediterranean, and rafts and floating and sub-floating long-lines for mussel (Mytilus galloprovincialis) culture, both in the Mediterranean and Atlantic. However, marine aquaculture in Morocco developed less rapidly than in neighbouring European countries. The National Institute of Marine Fisheries undertakes studies and experiments to support aquaculture development and diversification in terms of space, species and techniques. Spatial planning for marine site selection was initiated in 2000 to allow for aquaculture to integrate and enhance its development at national level. 
There is a 3-step procedure for aquaculture planning in Morocco: (1) characterise the current environmental, social and economic states of the target area; (2) define suitable zones for aquaculture inside the area using GIS tools and a participative approach, including the selection of suitable species and techniques; and (3) assessment the environmental impact of the defined aquaculture project. Criteria and requirements taken into consideration are those adopted by the European Union. This procedure allows definition of a specific zone to be dedicated exclusively for aquaculture purposes, without any conflicts of space or interest. It also allows local integration of aquaculture activities into maritime public domain, with a concession for a determined period (generally 20 yr and renewable). Aquaculture farmers are required to undertake regular environmental monitoring of their farm site annually. The first aquaculture plan was established for Dakhla Bay in early 2000 and since then, 4 other aquaculture plans were established ( 3 for lagoons and 1 for the coastal zone).

In Tunisia, the long coastline hosts numerous competitive and sometimes conflicting activities, including tourism, fishing, and aquaculture. This pressure on the coastal marine space has directly impacted procedures to assign sites to aquaculture activity. Indeed, the selection of aquaculture sites in sea areas remains a private initiative in Tunisia. The proposer must submit a preliminary study to obtain approval by the Interdepartmental Commission of Set Net. This committee (Decision of the Minister of Agriculture, 28 Sep 1995, Article 43) brings together the main ministries responsible for the use, management and control of maritime space. Representatives of local communities, chosen by local stakeholders, also take part in the work of the committee. The first approval granted by the committee reserves the requested area for aquaculture activity for $6 \mathrm{mo}$, to allow the development of technical proposals and appraisal of economic viability. At a later stage, it is necessary to obtain agreement by the National Agency for the Protection of the Environment based on the conclusions of the EIA. Once a final acceptance is granted, the area is allocated exclusively for aquaculture and becomes an aquaculture concession. Any activity other than aquaculture is prohibited in the concession area and in a $500 \mathrm{~m}$ buffer zone around the fish farm (Decision of the Minister of Agriculture, 28 Sep 1995, Article 49). Even the concession holder is not allowed to fishing in this area. Any modification or technical change must obtain prior an approval from a supervisory administrative body (Article 6). The concession holder is also held responsible for all irreversible changes of the environment (Article 13).

\section{POTENTIAL BENEFITS FROM ALLOCATED ZONES FOR AQUACULTURE (AZA)}

\section{Appropriate AZA selection}

As described above, mariculture is part of marine spatial planning in many regions of the world, based on different administrative approaches. The best scenario is that the spatial expansion of marine aquaculture is nested within the broader context of marine spatial planning to minimise adverse impacts on the environment and biodiversity, and to preserve ecosystem services at regional scale. Alternatively, selection of AZAs could be carried out by specific aquaculture spatial planning bodies, or site selection could even be made on a case by case basis, considering environmental and social aspects at local scale. In general, the selection of AZAs within the framework of coastal planning programmes, following different administrative and technical approaches, seems to be the optimal tool for a rational use of the marine space. However, sometimes the results are the opposite from what was intended, with unexpected negative effects on natural resources or on the aquaculture industry itself. It is necessary to balance properly demands for aquaculture development with the need to protect marine ecosystems (Douvere \& Ehler 2009). In order to avoid future problems, selection of AZAs must take account of current and future uses of ecosystem services and must be done in a participative way, under the ecosystem-approach to aquaculture, and within the framework of marine spatial planning to secure sustainable benefits from aquaculture without exceeding the resilience of natural systems (FAO 2010b).

In any case, conservation of habitats and of species of high ecological value, and maintenance of ecological biodiversity and water quality, will improve social acceptance of aquaculture (GFCM 2011). In addition to natural limiting factors, it is important to note that the social interactions with other human activities, together with conflicts on use and partitioning of resources in the much-exploited coastal zone, are constraints to be considered when aquaculture facilities are set up (IUCN 2009). Moreover, aquaculture is an economic activity more dependent on the maintenance of environmental quality than many others. Therefore spatial planning of the aquaculture sector should avoid economical losses due to environmental degradation (e.g high mortality because of diseases in Chile; Bustos-Gallardo 2013) or selection of sites with unsuitable oceanic conditions (e.g. bankruptcy due to escapes in La Palma Island; Toledo-Guedes et al. 2014). 


\section{Role of management in AZA implementation}

It is important to note that, following development of the spatial planning procedure for selection of the AZA, adoption of sustainable aquaculture is not necessarily guaranteed, as this depends on effective enforcement of regulations by the relevant authorities. The salmon industry crisis that resulted in widespread infection of farmed fish by ISA in 2007, serves as a recent example of bad management. This disease, first detected in Norway in 1984 (Asche et al. 2010), led to the collapse of production and of employment, and devastation of the environment. Official information for Chile, available from the national fisheries service (SERNAPESCA), records verified outbreaks due to the ISA virus at a total of 134 fish farms between August 2007 and July 2009. The spread of ISA across farms was very rapid because of the inaction of the authorities and farm companies. Bustos-Gallardo (2013) argues that, at the time of prevalence of the disease, the Chilean environmental authorities did not consider the available scientific information, demonstrating an inability of the political system to address the crisis. This failure had 2 facets: firstly, an investigative phase during which scientific explanations were sought but not found in the form needed for policy-making; and secondly an intervention phase when the tentative solutions focused on economic restructuring and financial considerations while failing to address long-term ecological implications. Spatial planning and AZA selection (AMA in Chile) were probably the most relevant and important factors for curbing the ISA crises, since some areas that had been identified as optimal for aquaculture had a very high density of farms, and the risk of outbreaks of disease had not been taken into consideration. This was evidenced by the failure to allocate safety distances between farms to mitigate the spread of disease. Criticism from the scientific community focused on the degree to which national environmental policy was subordinated to the economic strategy pursued by Chile over the previous $30 \mathrm{yr}$, which had allowed excessive farm densities in some coastal regions. One of the most important and debated aspects of the recommendations from a joint working group was the establishment of 'barrios' (i.e. groups of farming activities in the same neighbourhood). Wherever there were at least 3 contiguous concessions, a group of owners could request to be declared a 'barrio', so as to coordinate their seeding and harvesting operations, application of antibiotics or other chemicals, and most importantly, to ensure better control and containment of future disease out- breaks. Governmental incentives were offered to the farm owners to relocate at a greater distance from other farms and operations; but the need for adequate spacing between farms, following the long experience of Norwegian companies growing Atlantic salmon, should have been included as a criterion for AZA selection in advance. Currently there are concerns because of changes made to the previous Fisheries and Aquaculture Regulations of 2010, which allow establishment of new AZAs in ISA-free sites for farm relocation. This would result in salmon farming activities moving south (into the Magallanes region); however, there is no robust scientific evidence to support such a measure (Vega-Salinas 2013). A panel of fish health experts weighted the risk factors predictive of the spread of the ISA virus among barrios in Chile, and defined fish density and site selection as 2 of the most important aspects to consider (Gustafson et al. 2014). The salmon crisis in Chile is an example of bad environmental governance, which raises important questions about the science-policy interface, and the extent to which current arrangements have the capacity to lead to appropriate spatial planning for the sustainable management of natural resources.

Another example of unintended adverse outcomes resulting from inappropriate spatial planning and implementation of AZAs is the new Turkish legislation for site selection, which requires fish farms to relocate offshore to 2 designated AZAs. Prior to this legislation, there were 127, mostly small farms, located in small semi-enclosed inlets in Gulluk Bay. As a result of a further amendment to the Turkish law, the fish farms were unable to fulfil new criteria and were compelled to relocate to the offshore AZA during the period 2008-2009. Following relocation, an additional 81 new larger fish farms began to operate in Gulluk Bay and the annual production capacity was increased to $88000 \mathrm{t}$. Fish farms that were found to be in contravention of this new law, mostly small fish farms, were closed down by the authorities. Therefore, the new Turkish legislation negatively affected the small fish farms, which could not afford the financial investment required for reallocation, and led to concentration of farming activities in a few large-scale fish farms.

The review of AZAs makes it clear that in countries where aquaculture is a strategic sector, spatial planning, and/or environmental management for aquaculture have been implemented in diverse ways (Fig. 1). In simple terms, spatial aquaculture management might be classified based on: (1) the length of the coastline of the country; (2) the governance level 


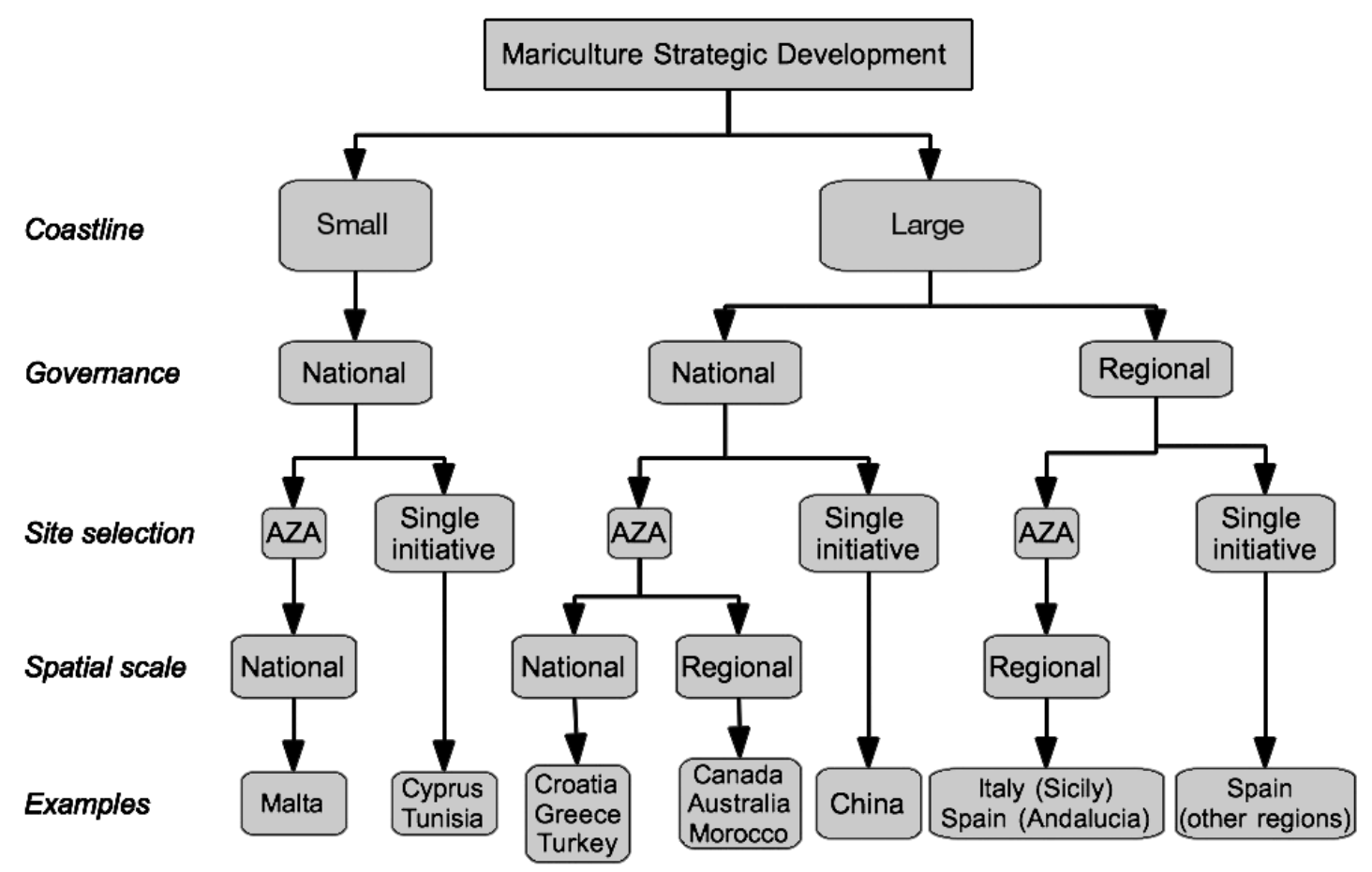

Fig. 1. Classification of case studies of Allocated Zones for Aquaculture (AZAs) included in the present study, relative to (1) the length of the coastline of the country, (2) the governance level, (3) the site selection procedure (based on previous spatial planning or relying on private single initiative) and, in the event of spatial planning, (4) the spatial scale of AZA selection

(national or regional); (3) whether site selection is framed by previous spatial planning or relies on private initiative; and, if a spatial planning process exists, (4) the spatial scale of AZA selection (the entire national coastline or by regions). Logically, the management strategy depends on the size of the coastline. Small countries (with less than $2000 \mathrm{~km}$ of coastline) can more easily develop AZA-based site selection for the total available marine space (74 countries from a total of 149, following the World Resources Institute, e.g. Malta), because governance is at the national level. However, this does not always occur, as noted for Cyprus and Tunisia, small countries where site selection depends very much on individual initiatives. For larger countries, site selection is strongly dependent on the administrative structure (i.e. the distribution of central and regional legal authorities, among states, autonomous regions, provinces and counties). By contrast, some countries with a very long coastline, such as Turkey, Croatia and Greece, have developed spatial planning at the national level. At this level, success depends principally on how different administrative bodies coordinate AZA implementation within the total national territory (for an example, see Karka et al. 2011). It is common for a regional approach to be adopted for selection of an AZA, especially in regions in which aquaculture is a priority sector (e.g. British Columbia in Canada, Queensland in Australia or the Mediterranean coast of Morocco). Despite the considerable efforts at both national and regional levels to developing guidelines for the management of aquaculture activities, there are many examples where spatial planning is not correctly implemented at the regional scale; these include cases in which site selection depends on single business initiatives (e.g. the Valencian Community in Spain). Some large Asian countries, for example China, which has the highest aquaculture production growth worldwide, have general marine spatial planning guidelines that are embedded in aquaculture planning regulations, and which are based on a 'site by site' management plan. It appears that China considers the physical and production aspects of aquaculture as driving forces for spatial planning, without taking account of environmental aspects, social acceptance or potential user conflicts. Such guidelines and regulations could lead to enhanced user conflict and environmental degradation at the regional scale. In such cases, creation of 'social spaces' to allow space for users and stakeholders to interact is essential for optimal AZA selection and designation. After top-down site selection, local issues including farming activities that exceed the carrying capacity, environmental pressure due to 


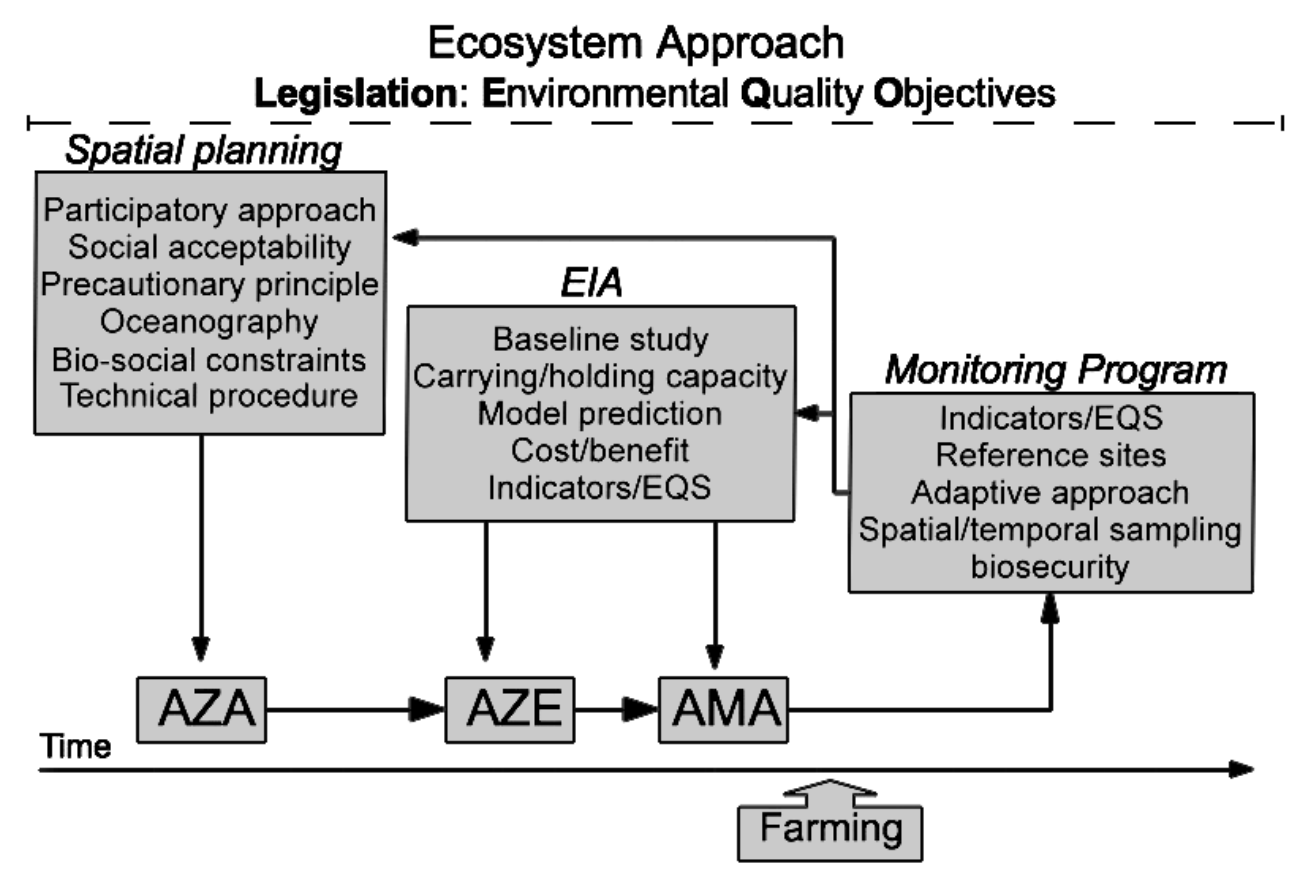

Fig. 2. Technical procedure for correct full environmental management of aquaculture, which must include the definition of an Allocated Zone for Aquaculture (AZA), an Environmental Impact Assessment (EIA), definition of an Allowable Zone of Effect (AZE) and an Aquaculture Management Area (AMA) and, following the initiation of farming activity, development of monitoring programmes (modified from Sanchez-Jerez \& Karakassis 2011)

problems with area zoning scheme enforcement, and lack of effective monitoring and of legislation on effluent discharge, are the main bottlenecks that are currently limiting appropriate aquaculture site selection and carrying capacity management in China (Chen et al. 2011).

In all these scenarios, successful development of aquaculture in the coastal zone requires the establishment of a regulatory framework for coastal and offshore aquaculture, and consideration of important aspects such as licensing, site selection and monitoring, to keep possible harmful effects on the marine environment under control. The challenge for governments is to ensure that appropriate governance measures are implemented. Without effective governance, there will be misallocation of resources or stagnation of production, and this affects all businesses, whether aquaculture or any other. Communication across administrative levels must be effective and transparent and with mechanisms for societal participation. Regulatory procedures can be conducive to investment or may instead hinder all entrepreneurial initiatives in aquaculture. Without the rule of law, there will be little predictability and security. In such situations, farmers have no incentive to take risks or to invest. Rent-seeking rather than efficiency becomes rational behaviour for resource users, with a resulting loss of productivity (Hishamunda et al. 2014).
Development of full environmental management of aquaculture, beyond marine spatial planning, should include EIAs and monitoring programmes and, for each AZA, definition of the corresponding Allowable Zone of Effect (AZE) and Aquaculture Management Area (AMA) (Fig. 2). Under the umbrella of an ecosystem approach, national and/or regional legislation should define the Environmental Quality Objectives (EQOs), which ensure the safeguarding of ecosystem services. For the selection of AZAs, it is important to establish a regulatory process that clearly identifies where aquaculture facilities can be located and for how long. A technical procedure of site selection, using biological and oceanographic information and taking into consideration ecological and social constraints (i.e. carrying capacities), must also be applied in defining the AZA. This process must follow a participatory approach, which considers the social acceptability of aquaculture in the area. For each AZA, an EIA will: (1) forecast the potential environmental and socio-economic impact of aquaculture; (2) define the spatial extent of the AZE (SanchezJerez \& Karakassis 2011) for a determinate level of production and type of mariculture; (3) estimate the area of influence around the AZE; and (4) define the AMA. The EIA will also facilitate collection of baseline environmental information, enable estimation of the holding/carrying capacity (see a review in Ross et 
al. 2013) and define the indicators to be used by the monitoring programme, as well as values for Environmental Quality Standards (EQS). Therefore, establishment of the AMA should be the last step, incorporating a management plan which includes a monitoring programme, and considers biosecurity aspects and social and environmental constraints. Estimation of carrying/holding capacity and setting a limit to maximum production would also be fundamental. Monitoring results should be made public and communicate the status of the AZA to the public in an accessible way (e.g. using a traffic light system). When farming is initiated, monitoring programmes should ensure that the EQS are within optimal limits using pre-defined indicators of environmental change, with an appropriate spatial and temporal sampling design. Fortunately, all these aspects are considered to a greater or lesser extent by most countries where aquaculture is an important sector.

\section{CONCLUSIONS}

Because management of marine aquaculture should be ecosystem-based, balancing ecological, economical, and social objectives for sustainable development, we suggest that national or regional authorities in charge of coastal zone management must use spatial planning for identifying suitable AZAs, and implement them more widely. Development of aquaculture spatial plans as a framework for the establishment of AZAs, will help avoid negative externalities, provide business opportunities, and decouple environmental degradation and aquaculture development. It is essential that, for AZAs to be effective, they should be accompanied by a clear national/subnational (regional or other national administrative subdivision) regulatory framework and regulated under optimal governance, in which the different procedures for licensing and leasing aquaculture activities are clearly outlined. Finally, site selection and definition of AZAs are only the first step towards sustainable aquaculture. To follow up, one or several AMAs should be defined within an AZA, each with a management plan in accordance with the EIA, ongoing monitoring, and provisions for adaptive management. There should be appropriate stakeholder participation, and information about the AZA should be made available to the public.

The General Fisheries Commission for the Mediterranean (GFCM), a regional fisheries management organisation with a specific mandate for aquaculture, adopted a specific resolution on AZAs in 2012, in which marine spatial planning, EIA and a monitoring programme are considered essential for the implementation of a regional strategy for the creation of AZAs, and as a priority for the responsible development and management of aquaculture activities in the Mediterranean and Black Sea (GFCM 2012). Further to this resolution, the Committee on Fisheries of FAO (2013b) emphasised the need for spatial planning to ensure the allocation of adequate space for aquaculture. It highlighted the benefits of spatial planning for multiple outcomes, including: (1) a more coordinated and integrated approach to the use and management of the environment; (2) accountability and transparency by involving relevant stakeholders at all levels; (3) a better understanding of the cumulative and combined effects of different uses of coastal resources and the interactions among resource users and between users and the environment; (4) a more effective mechanism for governments to deliver their commitments to sustainable development; (5) greater clarity on policy and decision-making; and (6) a better understanding of the changes required to improve different enabling policy and regulatory frameworks.

In a future, with improved technology, aquaculture systems will move away from inshore to open waters. Offshore mariculture may be an option to avoid issues of competition for space, reducing environmental impact and negative public perceptions (Lovatelli et al. 2013). In this emerging scenario, AZAs also need to be selected by spatial planning processes within the exclusive economic zones of each country; or even further, beyond the 200 nautical miles belt of national jurisdiction (Hishamunda et al. 2014). Therefore new analytical frameworks will be necessary to define appropriate aquaculture site selection, closely linked to aquaculture technological developments. Selection of an AZA should be an adaptive process, in order to respond to the potential beneficial and negative effects of climate change and weather uncertainty, some that must be taken into consideration for future marine spatial planning.

\section{LITERATURE CITED}

Arnold WS, White MW, Norris HA, Berigan ME (2000) Hard clam (Mercenaria spp.) aquaculture in Florida, USA: geographic information system applications to lease site selection. Aquacult Eng 23:203-223

ARPA (Agenzia Regionale per la Protezione Dell'Ambiente) Sicilia (2008) Linee guida per la realizzazione di impianti di maricoltura in Sicilia. Regione Siciliana, Palermo

Arriaga L, Martinez J (2003) Subsecretaria de Recursos Pesqueros. Plan de ordenamiento de la pesca y acuicultura del Ecuador. (accessed 20 Sep 2014) 
Asche F, Hansen H, Tveteras R, Tveterås S (2010) The salmon disease crisis in Chile. Mar Resour Econ 24: 405-411

Bustos-Gallardo B (2013) The ISA crisis in Los Lagos Chile: a failure of neoliberal environmental governance? Geoforum 48:196-206

Cao L, Wang WM, Yang Y, Yang CT, Yuan ZH, Xiong SB, James D (2007) Environmental impact of aquaculture and countermeasures to aquaculture pollution in China. Environ Sci Pollut R 14:452-462

Chapela Pérez R (2009) Review on cage aquaculture licensing procedures: a focus on Chile, Greece, Norway, Spain and the United States of America. In: FAO Regional Commission for Fisheries. Report of the Regional Technical Workshop on Sustainable Marine Cage Aquaculture Development, Muscat, 25-26 January 2009. FAO Fish Aquacult Rep 892, FAO, Rome, p 95-130

Chapela R, Ballesteros M (2011) Procedures for site selection, regulatory schemes and EIA procedures in the Mediterranean. In: Report of the 35th session of the General Fisheries Commission for the Mediterranean (GFCM). Site selection and carrying capacity in Mediterranean marine aquaculture: key issues (WGSCSHoCMed). Unpublished document (GFCM:XXXV/2011/ Dma.9), p 91-136. http://bit.ly/GFCM-XXXV-2011Dma9 (accessed 15 Feb 2014)

Chen LX, Zhu CB, Dong SL (2011) Aquaculture site selection and carrying capacity management in China. Guangdong Agricult Sci 21:1-7

Dempster T, Sanchez-Jerez P (2008) Aquaculture and coastal space management in Europe: an ecological perspective. In: Holmert M, Black K, Duarte CM, Marbà N, Karakassis I (eds) Aquaculture in the ecosystem. Springer, Dordrecht, p 87-116

DFO (Fisheries and Oceans Canada) (2005) Assessment of finfish cage aquaculture in the marine environment. Science Advisory Report 2005/034, DFO Canadian Science Advisory Secretariat, Ontario

Díaz R, Rabalais NN, Breitburg DL (2012) Agriculture's impact on aquaculture: hypoxia and eutrophication in marine waters. Organisation for Economic Co-operation and Development. www.oecd.org/tad/sustainableagriculture/ 49841630.pdf (accessed 20 Feb 2014)

Douvere F, Ehler CN (2009) New perspectives on sea use management: initial findings from European experience with marine spatial planning. J Environ Manage 90: 77-88

Duarte CM, Holmer M, Olsen Y, Soto D and others (2009) Will the oceans help feed humanity? Bioscience 59: 967-976

European Commission (2014) Natura 2000 network. ec. europa.eu/environment/nature/natura2000 (accessed 16 Feb 2014)

FAO (Food and Agriculture Organisation of the United Nations) (2010a) The state of world fisheries and aquaculture 2010. FAO, Rome

FAO (2010b) Aquaculture development. 4. Ecosystem approach to aquaculture. FAO Technical Guidelines for Responsible Fisheries 5, Suppl 4. FAO, Rome

FAO (2012a) The state of world fisheries and aquaculture 2012. FAO, Rome

FAO (2012b) FAO Fishstat Plus database, Fisheries and Aquaculture Information and Statistics Service www.fao. org/fishery/statistics/ (accessed 8 Dec 2013)

FAO (2013a) The FAO Fisheries and Aquaculture Depart- ment's efforts in implementing the recommendations of the past sessions of the COFI sub-committee on Aquaculture. Seventh session of the Sub-Committee on Aquaculture (SCA) of the FAO Committee on Fisheries (COFI), St. Petersburg, 7-11 Oct 2013

FAO (2013b) Applying spatial planning for promoting future aquaculture growth. In: Seventh session of the SubCommittee on Aquaculture (SCA) of the FAO Committee on Fisheries (COFI), St. Petersburg, 7-11 October 2013, Discussion document: COFI:AQ/VII/2013/6. www.fao.org/ 3/a-mk029e.pdf

GFCM (General Fisheries Commission for the Mediterranean) (2011) Site selection and carrying capacity in Mediterranean marine aquaculture: key issues (WGSCSHoCMed). Unpublished document (GFCM:XXXV/ 2011/Dma.9). http://gfcmsitestorage.blob.core.windows. net/documents/web/GFCM/35/GFCM_XXXV_2011_ Dma.9.pdf (accessed 15 Feb 2014)

GFCM (2012) Resolution GFCM/36/2012/1 on guidelines on allocated zones for aquaculture (AZA). http://bit.ly/ Resolution-GFCM-36-2012-1 (accessed 16 Feb 2014)

GMFMC (Gulf of Mexico Fishery Management Council) and NOAA (National Oceanic and Atmospheric Administration) (2009) Fishery management plan for regulating offshore marine aquaculture in the Gulf of Mexico. GMFMC, Tampa, FL

Gustafson L, Antognoli M, Fica ML, Ibarra R and others (2014) Risk factors perceived predictive of ISA spread in Chile: applications to decision support. Prev Vet Med 117:276-285

Hall CM (2001) Trends in ocean and coastal tourism: the end of the last frontier? Ocean Coast Manage 44:601-618

Hauraki Gulf Forum (2011) Spatial planning for the Gulf: an international review of marine spatial planning initiative and application to the Hauraki Gulf. Hauraki Gulf Forum, Auckland. www.aucklandcouncil.govt.nz/EN/ AboutCouncil/representativesbodies/haurakigulfforum/ Documents/Spatialplanforthegulf.pdf (accessed 16 Feb 2014)

Hishamunda N, Ridler N, Martone E (2014) Policy and governance in aquaculture: lessons learned and way forward. FAO Fish Aquacult Tech Pap 577, FAO, Rome

> Hutchings JA, Côté IM, Dodson JJ, Fleming IA and others (2012) Is Canada fulfilling its obligations to sustain marine biodiversity? A summary review, conclusions and recommendations. Environ Rev 20:353-361

IUCN (International Union for the Conservation of Nature) (2009) Guide for the sustainable development of Mediterranean aquaculture. 2. Aquaculture site selection and site management. IUCN, Gland

Jessen S (2011) A review of Canada's implementation of the Oceans Act since 1997-from leader to follower? Coast Manage 39:20-56

Karka H, Kyriazopoulos E, Kanellopoulou K (2011) Spatial planning for aquaculture: a special national framework for resolving local conflicts. In: 51st Congress of the European Regional Science Association (ERSA), Barcelona, 30 Aug-3 Sep 2011. www-sre.wu.ac.at/ersa/ersaconfs/ ersa11/e110830aFinal01592.pdf (accessed 26 Feb 2014)

Knapp G (2008) Economic potential for US offshore aquaculture: an analytical approach. In: Rubino M (ed) Offshore aquaculture in the United States: economic considerations, implications and opportunities. NOAA Tech Memo NMFS F/SPO-103, US Dept of Commerce, Silver Spring, MD, p 15-50 
Larsen J, Roney M (2013) Farmed fish production overtakes beef. Earth Policy Institute, Washington, DC. www.earthpolicy.org/plan_b_updates/2013/update114 (accessed 20 Feb 2014)

Longdill PC, Healy TR, Black KP (2008) GIS-based models for sustainable open-coast shellfish aquaculture management area site selection. Ocean Coast Manage 51: $612-624$

Lovatelli A, Aguilar-Manjarrez J, Soto D (eds) (2013) Expanding mariculture farther offshore: technical, environmental, spatial and governance challenges. FAO Technical Workshop, 22-25 Mar 2010, Orbetello. FAO Fish Aquacult Proc 24, FAO, Rome

MABF (Ministry of Agriculture Bureau of Fisheries) (2011) China fisheries yearbook. China Agriculture Publishing Company, Beijing

Macías JC, Lozano I, Alamo C (2006) Zonas idóneas para el desarrollo de la acuicultura en espacios marítimoterrestres de Andalucía. Consejería de Agricultura y Pesca, Junta de Andalucía, Málaga

Marra J (2005) When will we tame the oceans? Nature 436: 175-176

MEF (Ministry of Environment and Forestry) (2007) The notification to identify the closed bay and gulf qualified sensitive where fish farms are not suitable to be established in the seas. Turkish Official Gazette 26413 (in Turkish)

MEF (Ministry of Environment and Forestry) (2009) Monitoring regulations for fish farms. Turkish Official Gazette 27257 (in Turkish)

Niklitschek E, Soto D, Lafon A, Molinet C, Toledo P (2013) Southward expansion of the Chilean salmon industry in the Patagonian fjords: main environmental challenges. Rev Aquacult 5:172-195

NOAA (National Oceanic and Atmospheric Administration) (2011). Marine aquaculture policy. www.nmfs.noaa.gov/

Editorial responsibility: Kenneth Black, Oban, UK aquaculture/docs/policy/noaa_aquaculture_policy_2011. pdf (accessed 26 Feb 2014)

Pattanaik C, Prasad SN (2011) Assessment of aquaculture impact on mangroves of Mahanadi delta (Orissa), east coast of India using remote sensing and GIS. Ocean Coast Manage 54:789-795

> Primavera JH (1997) Socio-economic impacts of shrimp culture. Aquacult Res 28:815-827

Ross LG, Telfer TC, Falconer L, Soto D, Aguilar-Manjarrez J (eds) (2013) Site selection and carrying capacities for inland and coastal aquaculture. FAO/Institute of Aquaculture, University of Stirling, Expert Workshop, 6-8 Dec 2010, Stirling. FAO Fish Aquacult Proc 21, FAO, Rome

Sanchez-Jerez P, Karakassis I (2011) Allowable zone of effect for Mediterranean marine aquaculture (AZE) (WGSCSHoCMed). Unpublished document (GFCM:CAQ/2012/ CMWG-5/Inf.11). http://bit.ly/GFCM-CAQ-AZE-2011 (accessed 15 Feb 2014)

State of Queensland (2011) Great Sandy Regional Marine Aquaculture Plan. Department of Employment, Economic Development and Innovation, Brisbane. www. daff.qld.gov.au/_data/assets/pdf_file/0019/65710/finalGSRMAP.pdf (accessed 16 Feb 2014)

SUBPESCA (2014) Áreas Aptas para la Acuicultura (AAA). Subsecretaría de Pesca y Acuicultura, Gobierno de Chile, Santiago. www.subpesca.cl/institucional/602/w3article-915.html (accessed 15 Sep 2015)

Toledo-Guedes K, Sanchez-Jerez P, Brito A (2014) Influence of a massive aquaculture escape event on artisanal fisheries. Fish Manag Ecol 21:113-121

VanderZwaag DL, Hutchings JA, Jennings S, Peterman RM (2012) Canada's international and national commitments to sustain marine biodiversity. Environ Rev 20:312-352

Vega-Salinas D (2013) Uso de las concesiones acuícolas de mar en la industria salmonera de Chile. Sustain Agricult Food Environ Res 2:1-35

Submitted: March 12, 2014; Accepted: October 30, 2015 Proofs received from author(s): December 11, 2015 